\title{
A ideologia do comércio internacional
}

\section{Resumo}

O presente artigo procura discutir os pressupostos ideológicos da construção da teoria do comércio internacional. Para tanto, resgata aspectos da política mercantilista, as críticas a esta formuladas pelos primeiros teóricos da doutrina liberal, a teoria das vantagens absolutas de Adam Smith e ainda a teoria das vantagens comparativas de David Ricardo. Posteriormente, faz-se uma breve discussão sobre a validade da teoria do valor trabalho, postulada por Ricardo e defendida por Marx e, finalmente, chama-se a atenção para o anacronismo da teoria das vantagens comparativas frente à atual situação da economia capitalista.

\section{Abstract}

The present article has the objective of discussing the ideological presuppositions of the international commerce theory. For this, it takes aspects of the mercantilist police, the critical which are formulated against it by the first theorists of liberal doctrine, as the Adam Smith' absolute advantages theory and also the David Ricardo" comparative advantages theory. Afterward, it makes a brief discussion about the validity of the Work Value theory, postulated by Ricardo and defended by Marx and, finally, it pay attention to the anachronism of the comparative advantages theory face to the capitalist economy real situation.

Na vida social, as idéias e as teorias apresentam uma dupla faceta. De um lado, são úteis para explicar e justificar as relações sociais existentes. De outro, idéias e teorias também se colocam no campo da transformação e do questionamento da ordem social vigente. Graças a este caráter dia- lético, tais manifestações humanas são fruto da existência real das pessoas em sociedade. Desta forma, a prevalência de um ou de outro aspecto das idéias e/ou teorias é determinada pelo embate social e pela hegemonia de um ou outro interesse de classe em questão, e não da existência de idéias inatas ou naturais, que independem da História.

A Economia Política, que tem por pretensão a universalidade que o status de Ciência pode lhe conferir, não deixa de estar sujeita a todos os problemas advindos de sua construção histórica, qual seja, de ser estruturada de acordo com os interesses sociais e objetivando resolver problemas específicos do meio que the deu vida, no caso o capitalismo europeu. Conceitos como individualismo, acumulação, abstinência, racionalidade, eficiência, eficácia, lucro, vantagem comparativa etc. não podem ser estendidos a todos os povos do planeta como se fossem efetivamente universais.

Não obstante, à medida que a sociedade européia, através do uso da força, conseguiu submeter os demais povos do mundo, sua ideologia, suas mercadorias e seus objetivos de acumulação foram transformados em coisas naturais e universais. Tome-se como exemplo os carregamentos de pau-brasil que partiam da costa brasileira rumo à Europa, ao longo do século XVI. De um lado havia o europeu (português ou francês), ávido por mais e mais toras de madeira e pelo lucro proporcionado pela sua comercialização; de outro, o indígena, perplexo por não conseguir compreender aquela lógica de trabalhar desenfreadamente para acumular coisas como se a natureza não fosse capaz de prover às gerações vindouras os bens necessários à perpetuação da espécie. Ora, o que é natural para o primeiro é insensatez para o segundo, e vice-versa.

Talvez a Economia Política apresente também

*Doutor em História Econômica - FFLCH/USP. Professor do curso de Ciências Econômicas da Fundação Armando Álvares Penteado. Professor e Coordenador do curso de Ciências Econômicas das Faculdades Integradas "Campos Salles". 
uma certa característica "étnica", ou seja, européia, algo que possivelmente já havia sido intuído pelo insuspeito John K. Galbraith, em sua A era da incerteza. Neste documentário, editado em forma de livro, o autor chegou a ironizar o fato de que os fundadores da Economia Política eram, ‘com raras exceções, britânicos. Compartilhe-se de sua fina ironia:

"Seria temerário, e talvez até um tanto perigoso nos dias de hoje, propor uma teoria étnica dos economistas. Todas as raças produziram notáveis economistas, com exceção dos irlandeses que indubitavelmente podem dedicar sua devoção a artes mais elevadas. Mas, em relação à sua população, ninguém pode contestar a eminência dos escoceses, como devem ser chamados com toda propriedade. (...) A única concorrência mais séria seria da parte dos judeus".

De qualquer modo, é fato que a Economia Política começou a tomar corpo como um sistema racional e articulado, quando a aristocracia francesa começou a se opor aos rumos da política mercantilista, que até o começo do século XVIII era firmemente apoiada pelo Estado absolutista, sendo Colbert seu mais ardoroso defensor. Os fisiocratas, críticos do mercantilismo, tendo François Quesnay à frente, foram os primeiros estudiosos a sugerir o livre comércio e a não-intervenção do Estado na economia. Antes de tratarmos da crítica às políticas comerciais da era mercantilista, faz-se necessário explicitar seus pressupostos e os fundamentos.

\section{Mercantilismo e comércio exterior}

O sistema mercantilista, que toma contornos no século $\mathrm{XV}$, é fruto de profundas transformações na economia, na sociedade e na cultura européias. O Estado e a organização política, até então instáveis e fragmentados devido ao grande poder dos senhores feudais, gradativamente passaram a ser centralizados em um Estado Nacional, dirigido por um monarca absolutista. Esta nova organização surgiu, dentre outras motivações, da necessidade de se fazer frente ao desenvolvimento comercial e à necessidade do grupo mercantil de eliminar entraves ao seu negócio. O Estado nacional, desde então, passou a apoiar os mercadores dentro e fora de suas fronteiras.

Este relacionamento simbiótico entre Estado e camada mercantil devia-se ao fato de os tributos cobrados dos comerciantes representarem a principal fonte de receitas do soberano. Por outro lado, quanto maior a quantidade de riquezas, maior o poder do soberano para estender sua supremacia a outros territórios. Maior território também significava maiores potencialidades de lucro para a camada mercantil. $\mathrm{O}$ objetivo estratégico das políticas mercantilistas era o de ampliar a riqueza e o poder do Estado nacional (e de seu grupo mercantil) em detrimento do poder de outros.

Durante a prevalência das políticas mercantilistas, entre os séculos XVI e XVIII, o principal indicador de riqueza de um país era a quantidade de metais preciosos acumulados nos cofres do Estado. As fontes de metais preciosos, como se sabe, podem ser a exploração de jazidas dentro do próprio território, a conquista de territórios para a sua exploração ou, ainda, através de uma balança comercial superavitária. Como a maior parte das potências européias do século XVI não teve a "sorte" da Espanha em dominar o México e o Peru, concentremo-nos na última forma legal de obtenção de metais preciosos: o comércio internacional ${ }^{2}$.

A política mercantilista procurava criar as condições para que o país pudesse vender mais bens aos estrangeiros do que comprar destes. A estrutura colonial, por exemplo, criava um espaço privilegiado, para que a metrópole vendesse

${ }^{1}$ GALBRAITH, John K. A era da incerteza. São Paulo: Pioneira, 1984. p. 3-4.

${ }^{2}$ Não se pode perder de vista a pirataria como um mecanismo de apropriação de metais preciosos. A Inglaterra, nos tempos da Rainha Virgem, chegou mesmo a patrocinar piratas, como Francis Drake, que chegou a ser condecorado com o título de Lord, após roubar um carregamento de metais preciosos, oriundo do México, que se dirigia à Espanha. 
bens manufaturados às colônias e comprasse delas, a preços aviltados, os gêneros que necessitasse. Para garantir privilégios à classe mercantil, os governos mercantilistas incentivaram a criação de Companhias de Comércio, que monopolizavam as transações ultramarinas. As Companhias das Índias, tanto holandesas como inglesas ou francesas, visavam a incrementar e controlar as relações comerciais entre a metrópole e as colônias, ou ainda conquistar e administrar territórios. O poder destas companhias era de tal ordem que chegavam a organizar exércitos e cobrar impostos, funcionando como um poder para-estatal nas áreas coloniais.

Outra forma de evitar a "sangria de ouro" seria a de criar uma estrutura econômica o mais auto-suficiente possível. Para tanto, o Estado controlava tanto a exportação de gêneros agrícolas como chegava a estimular a criação de manufaturas que não somente pudessem substituir itens importados como também exportar a produção excedente.

$\mathrm{O}$ apoio às manufaturas, principalmente na Inglaterra e na França, passava pelas restrições à importação de bens similares, pela imposição de taxas proibitivas e até mesmo, como no caso francês, pela criação de manufaturas estatais. Este apoio era justificado pelo fato de que as novas manufaturas não teriam condição de competir com a produção de países mais especializados e, portanto, com menor preço de mercado.

Também visando ao aumento da competitividade das manufaturas nacionais, por intermédio da redução do preço das mercadorias, o Estado chegava mesmo a proibir a exportação de matérias-primas e alimentos, quando os preços internacionais estavam elevados, e a incentivar sua importação quando os preços internos estavam altos. No caso dos alimentos, tais medidas eram justificadas pela necessidade de se manterem baixos os níveis salariais na manufatura, tornando as mercadorias locais mais competitivas frente às concorrentes.
A política mercantilista procurava evitar a saída de metais preciosos por todos os lados. Um bom exemplo disto foi o Ato de Navegação, decretado por Cromwell, em 1651, que determinava que as mercadorias importadas pelos ingleses somente poderiam ser transportadas por navios ingleses ou do país exportador. Da mesma forma, as exportações inglesas somente poderiam ser transportadas por navios ingleses ou do país importador. Tal medida tinha um endereço: contrabalançar o predomínio naval da Holanda ${ }^{3}$. Como conseqüência, os holandeses entraram em guerra com a Inglaterra, entre 1652-1654. Com a vitória, os ingleses estabeleceram sua hegemonia naval, que duraria até o início da primeira guerra mundial, em 1914.

Efetivamente, o postulado de balança comercial superavitária e a aplicação de políticas que visassem a alcançar este fim levavam as nações européias, potencialmente, a uma situação limite que somente poderia ser resolvida pela guerra, pois, afinal, é impossível a todos os países, simultaneamente, apresentar saldo positivo em suas balanças comerciais. A este respeito, complementa Leo Huberman:

"Vemos que a crença de que 'não há nada mais importante e necessário para o bem geral do Estado' do que a redução do comércio e da indústria de um Estado rival só poderia levar a uma coisa: guerra. $\mathrm{O}$ fruto da política mercantilista é a guerra. A luta pelos mercados, pelas colônias - tudo isso mergulhou as nações rivais numa guerra após outra". ${ }^{4}$

Restrições morais à guerra não foram as únicas críticas à política mercantilista. Agricultores reclamavam contra as restrições ao livre comércio de alimentos e matérias-primas; o metalismo era responsabilizado pela alta inflação; comerciantes individuais reclamavam do excessivo poder das Companhias de Comércio. Por conseqüência, pensadores começavam a formular idéias

\footnotetext{
${ }^{3}$ A medida formulada por Cromwell tratava-se de um sério golpe no comércio holandês, que transportava, à época, mais de 90\% das cargas da Europa ocidental.

${ }^{4}$ HUBERMAN, Leo. História da riqueza do homem. Rio de Janeiro: Zahar, 1971. p. 142.
} 
acerca do caráter arbitrário e antinatural da intervenção estatal. As idéias "liberalizantes" colocavam o mercantilismo em xeque.

\section{A defesa do livre comércio}

A fundamentação das críticas ao mercantilismo e da posterior formulação da Economia Política clássica encontra-se nas transformações radicais das concepções relativas ao conhecimento científico que ocorreu ao longo do século XVII. O triunfo do método cartesiano (René Descartes, 1596-1650) influenciou decisivamente todos os campos do conhecimento humano, inclusive a pesquisa econômica.

método cartesiano tinha como pressuposto fundamental a dúvida, da mesma forma como via o mundo (a natureza) como uma unidade que poderia ser compreendida pela inteligência humana através de um método científico que revelasse a sua mecânica. Assim, se afastava da tradição aristotélica (e também da religião) que partia de pressupostos fundamentais e estáticos para a compreensão da realidade. Em sua obra Discurso do Método (1637), Descartes definia as quatro regras fundamentais de seu método: (a) só aceitar como verdadeiro o que está claro e não suscita dúvidas; (b) dividir cada problema em tantas partes quantas forem necessárias; (c) analisar cada parte com clareza e plenamente, acrescentando-a ao conhecimento do todo; (d) não deixar de levar em conta nada que possa ser fonte de erro. Pelo método cartesiano é a experiência científica que confere um caráter universal a um postulado. Também Descartes desenvolveu a Geometria Analítica, que passou a ser uma linguagem da ciência.

Assim como a natureza era vista como uma máquina, cujo funcionamento era explicável pelo conhecimento de leis, a sociedade também pas- sou a ser compreendida como uma máquina artificial e que o ser humano não passava também de um animal. Portanto, os mesmos princípios utilizados para a compreensão da natureza poderiam ser utilizados para a explicação da sociedade. Pensadores como Thomas Hobbes (1588-1679), John Locke (1632-1704) e David Hume (1711-1776) procuraram explicitar as leis (e, conseqüentemente, o Direito) naturais que regem a sociedade. Dentre estas, podem ser destacados: ênfase no individualismo, direito à integridade pessoal, à liberdade de opinião, o direito natural à propriedade privada etc..

A economia, cujo funcionamento seria similar ao da natureza, foi um campo fértil para o desenvolvimento de certas "leis naturais" e, portanto, pretensamente universais. Veja-se como Henri Denis apreende um aspecto interessante da filosofia social naturalista de Locke, especificamente no campo da economia:

“... o fim da vida social é produzir a maior quantidade possível de coisas úteis; pensa que não há razão para preocupações com a maneira por que são repartidas entre os indivíduos, nem com as conseqüencias morais e espirituais de tal ou tal tipo de desenvolvimento econômico". ${ }^{6}$

Ora, do que se pode depreender, os autores que influenciaram o desenvolvimento da Economia Política clássica preocupavam-se em tomar as coisas como se apresentam, ou melhor, apresentavam como natural um estádio de desenvolvimento que somente seria aplicável àquela realidade em que se situavam os defensores de uma "economia natural". Não é consenso que o objetivo "essencial" da economia seja produzir a maior quantidade de coisas úteis, mas sim produzir bens úteis que satisfaçam determinadas ne-

\footnotetext{
${ }^{5}$ Os pressupostos do método de Descartes podem ser em parte apreendidos no trecho a seguir: "Há algum tempo eu me apercebi de que, desde meus primeiros anos, recebera muitas falsas opiniões como verdadeiras, e de que aquilo que depois eu fundei em princípios tão mal assegurados não podia ser senão mui duvidoso e incerto; de modo que me era necessário tentar seriamente, uma vez em minha vida, desfazer-me de todas as opiniōes a que até agora dera crédito, e começar tudo novamente desde os fundamentos, se quisesse algo de firme e de constante nas ciências." DESCARTES, René. Meditações. São Paulo: Nova Cultural, 1991. (Coleção Os pensadores). p. 167.
}

${ }^{6}$ DENIS, Henri. História do pensamento econômico. Lisboa: Livros Horizonte, 1987. p. 143. 
cessidades. Essa postura se inscreve nos marcos de uma sociedade capitalista mercantil e é justificada pela busca do lucro através de uma maior circulação de bens.

Feita esta digressão, na qual se situou o marco intelectual em que se inscreve a criação da Economia Política clássica, retorne-se ao eixo de nossa problematização, que é o desenvolvimento dos postulados do comércio internacional.

A primeira doutrina que procurou sistematizar o funcionamento da economia, compreendida como um fenômeno natural, foi a fisiocracia ("o poder da natureza”), cujo principal teórico foi o agricultor e cirurgião francês, François Quesnay (1694-1774). Este partia do pressuposto de que o funcionamento da vida econômica era similar ao funcionamento de um organismo vivo, conforme se pode verificar:

"O ato do movimento inscreve-se em dois fiéis de balança iguais em força e em ação, a saber: a destruição e a regeneração. Tal é toda a máquina da $\mathrm{Na}$ tureza... É no emprego e na regeneração, isto é, no consumo e na reprodução, que consiste o movimento que condensa a sociedade e que perpetua a sua duração. É por aí que as despesas dão vida à produção e que a produção repara as despesas. Esta circulação tem, como todas as outras, regras exatas de fluxo e refluxo, que impedem igualmente não só o esgotamento dos canais, mas também sua obstrução. São regras estas que tanto importa conhecer, não para provocar a intervenção de uma mão temerária em condutas cujo jogo natural depende unicamente da impulsão que lhes é própria e que não suportam nenhum socorro estranho, mas para evitar as que pode prejudicar - são estas regras tão importantes, e apesar disso tão pouco conhecidas, que vamos anatomizar(sic)".

Procurando anatomizar o processo econômico, Quesnay formulou o embrião da contabilidade nacional moderna, o Tableau Économique, em que tentava representar numericamente o mecanismo da vida econômica. Ao tratar a economia como um ser vivo, o cirurgião, por analogia, deduziu que qualquer ação externa sobre este organismo tenderia a romper o equilíbrio natural, gerando mais males do que curas. E qual poderia ser a ação externa à economia que tantos males poderia criar? A resposta é a intervenção estatal.

Também o Tableau procurava justificar o pressuposto fisiocrático de que somente a agricultura era capaz de gerar um excedente líqüido e que a manufatura era estéril na medida em que somente remunerava os fatores empregados na sua produção sem criar um valor superior à soma de seus custos. Tal fato, na visão de Quesnay, tornava a intervenção estatal visando a apoiar as manufaturas, essência da política mercantilista, mais irracional ainda.

O principal problema econômico que Quesnay gostaria de ver solucionado era a queda no padrão de vida dos agricultores, que havia sido provocada pela intervenção do Estado no mercado de cereais e também no de matérias-primas agrícolas. Conforme já se assinalou, o governo intervinha no comércio de cereais visando ao barateamento dos salários, uma das principais condições para o aumento da concorrência da manufatura francesa no comércio internacional. A solução para esse problema estaria na supressão de qualquer entrave ao livre comércio, facultando ao agricultor a liberdade de vender suas mercadorias onde encontrasse melhor preço. Tal princípio, de total liberdade do produtor, deveria, na opinião dos fisiocratas, ser estendido a todas as demais atividades econômicas. Surge daí a expressão que passa a ser a bandeira do liberalismo econômico: laissez-faire, laissez-passer!

As idéias dos fisiocratas seriam plenamente desenvolvidas do outro lado do Canal da Mancha, mais precisamente em 1776, quando Adam Smith publicou sua obra-prima: Investigações sobre a natureza e as causas da riqueza das nações ou, simplesmente $\mathrm{A}$ riqueza das nações. Smith distingue-se dos demais economistas que o antecederam, segundo E. K. Hunt:

“(...) não só por sua formulação acadêmica e pela vastidão de seus conhecimentos, como também porque

${ }^{7}$ QUESNAY, François. Philosophie rurale. Apud. DENIS, op. cit. p. 170. 
foi o primeiro a elaborar um modelo abstrato completo e relativamente coerente da natureza, da estrutura e do funcionamento do sistema capitalista. Via claramente que havia importantes ligações entre as principais classes sociais, os vários setores de produção, a distribuição da riqueza e da renda, o comércio, a circulação da moeda, os processos de formação de preços e o processo de crescimento econômico". ${ }^{8}$

O que tornava Smith superior aos fisiocratas era o fato de que também considerava produtiva a manufatura, não somente a agricultura, uma vez que o que deveria ser levado em consideração, segundo o autor, era o trabalho humano incorporado nas mercadorias. Em que pese sua importância, deter-se-á em sua obra apenas nos problemas relacionados ao comércio exterior. Segundo o autor, a origem da riqueza das nações é a divisão do trabalho, cuja principal motivação é a propensão dos indivíduos a trocar. Veja-se como o autor a justifica:

"Essa divisão do trabalho, da qual derivam tantas vantagens, não é, em sua origem, o efeito de uma sabedoria humana qualquer, que preveria e visaria esta riqueza geral à qual dá origem. Ela é conseqüência necessária, embora muito lenta e gradual, de uma certa tendência ou propensão existente na natureza humana que não tem em vista essa utilidade extensa, ou seja: a propensão a intercambiar, permutar ou trocar uma coisa pela outra". ${ }^{10}$

A divisão do trabalho ganha especial importância devido à especialização que lhe é inerente, viabilizando o intercâmbio comercial. Quanto maior a especialização, maior é a produtividade do trabalho, maior a riqueza criada em menor tem- po e, conseqüentemente, os custos são mais baixos, uma vez que, segundo Smith, o que define o valor de troca de uma mercadoria é o trabalho humano incorporado em sua produção, trabalho este que poderia ser mensurado pelo tempo ${ }^{11}$.

Assim como outros pensadores liberais, Smith acreditava que a sociedade era simplesmente formada pela soma de todos os indivíduos e, de forma similar, o sistema econômico era simplesmente a soma de todos os produtores individuais. Ora, se a divisão do trabalho e a especialização poderiam ser eficientes no âmbito da empresa, por que não seria ao nível da nação ou mesmo do mundo? Comprar do estrangeiro o que for mais barato e vender ao estrangeiro o que puder ser produzido com maior eficiência parece ser um axioma. Veja-se como Smith trata desta questão:

"O que é prudente na conduta de qualquer família particular, dificilmente constituirá insensatez na conduta de um grande reino. Se um país estrangeiro estiver em condições de nos fornecer uma mercadoria a preço mais baixo do que o da mercadoria fabricada por nós mesmos, é melhor comprá-la com uma parcela da produção de nossa própria atividade, empregada de forma que possamos auferir alguma vantagem. A atividade geral de um país, por ser sempre proporcional ao capital que the dá emprego, não diminuirá com isso, da mesma forma como não diminui a atividade dos profissionais acima mencionados; o que apenas resta é descobrir a maneira pela qual ela pode ser aplicada para trazer maior vantagem possível". 12

O comércio internacional é benéfico na visão de Smith, na medida em que se pode obter no estrangeiro produtos mais baratos, ou seja, produzidos de forma mais eficiente e a um menor

\footnotetext{
${ }^{8}$ E.K HUNT. História do pensamento econômico. Rio de Janeiro: Campus, 1981. p. 60.

${ }^{9}$ Os fisiocratas não diferem tanto de Smith. São os pais das idéias dele. Simplesmente, no Estado francês, não podiam defender abertamente a manufatura, o que de fato faziam ao pretender imposto único sobre a ... agricultura.

${ }^{10}$ SMITH, Adam. A riqueza das nações. Tradução Luiz J. Baraúna. v. 1. São Paulo: Nova Cultural, 1996. p. 73. (Coleção Os Economistas).

"Smith exemplifica a eficiência da divisão do trabalho ao descrever a manufatura de alfinetes, em que, através da divisão de tarefas e da especialização, um operário poderia produzir 4.800 peças, enquanto outro, trabalhando individualmente e sem divisão de tarefas, apenas 20. Ver. SMITH, op. cit., p.65-67.

${ }^{12}$ SMITH, op. cit., p.439.
} 
custo em trabalho, do que aqueles produzidos internamente. Custos mais baratos, muitas vezes, se relacionam a certas características do país produtor que dificilmente poderiam ser reproduzidas no país importador. Senão, veja-se:

"As vantagens naturais que um país tem sobre outros na produção de determinadas mercadorias por vezes são tão relevantes que todo mundo reconhece ser inútil concorrer com esses países. Utilizando-se vidros, viveiros e estufas pode-se cultivar excelentes uvas na Escócia, podendo-se com elas fabricar vinhos muito bons, com uma despesa aproximadamente trinta vezes superior àquela com a qual se pode importar de outros países vinhos pelo menos da mesma qualidade. Seria porventura uma lei racional proibir a importação de todos os vinhos estrangeiros, simplesmente para incentivar a fabricação de vinho clarete e borgonha?"13

Ainda segundo Smith, as vantagens que um país possui sobre outro não se restringem às vantagens naturais, podem ser estendidas às vantagens adquiridas, ou seja, àquelas em que a habilidade técnica seja superior à de outros países. Assim o autor raciocina:

“(...) não interessa se as vantagens que um país leva sobre outro são naturais ou adquiridas. Enquanto um dos países tiver estas vantagens, e outro desejar partilhar delas, sempre será mais vantajoso para este último comprar do que fabricar ele mesmo. A vantagem que um artesão tem sobre seu vizinho, que exerce outra profissão, é apenas uma vantagem adquirida; no entanto, os dois consideram mais vantajoso comprar de um outro artesão, do que cada um fazer aquilo que não é do seu ofício específico". ${ }^{14}$

Tal seria a teoria das vantagens absolutas de Smith. Por conta disto, a defesa do livre-comércio e da não intervenção estatal nos processos econômicos, além de atacar firmemente as doutrinas mercantilistas e protecionistas, passam a constituir a pedra fundamental da Economia Política clássica que a partir de então passa a se assumir como Ciência.

\section{Comércio internacional e especialização}

Os pressupostos de Smith seriam aprofundados por Thomas R. Malthus e David Ricardo, no começo do século XIX. Do ponto de vista do comércio internacional, seria Ricardo o principal teórico das virtudes do livre-comércio, sendo sua teoria das vantagens comparativas o fundamento das teorias neoclássicas vigentes até os dias atuais.

Faz-se necessário esclarecer que, enquanto os fisiocratas eram os defensores por excelência da agricultura, Ricardo foi um entusiasta da indústria e, como tal, formulou suas teses tendo em vista a superioridade inglesa no campo industrial. Por exemplo, defendeu a livre importação de cereais como medida para forçar a queda de seus preços, visando a manter baixos os níveis monetários dos salários. É de Ricardo a famosa "Lei de Ferro", que explica que o salário dos operários deve sempre se situar ao nível da sobrevivência, de forma a não permitir um aumento desenfreado do contingente de trabalhadores, nem a sua diminuição.

Dentre as contribuições de Ricardo à Economia Política, sua teoria do valor-trabalho teve grande repercussão, uma vez que conseguia fornecer uma explicação científica sobre o processo de formação dos preços (valor de troca) das mercadorias. Assim como Smith, Ricardo acreditava que o trabalho humano incorporado na produção de uma mercadoria seria o determinante do seu valor de troca. Assim sendo, define o autor:

"Se a quantidade de trabalho contida nas mercadorias determina o seu valor de troca, todo acréscimo nessa quantidade de trabalho deve aumentar o

\footnotetext{
${ }^{13}$ Idem, p. 440.

${ }^{14}$ SMITH, op. cit., p. 440.
} 
valor da mercadoria sobre a qual ela foi aplicada, assim como toda diminuição deve reduzi-lo". ${ }^{15}$

A teoria do valor-trabalho teve grande valia para que Ricardo desenvolvesse a sua teoria de comércio internacional, baseada nas vantagens comparativas de cada país. Com essa teoria, nosso autor superava os postulados de Smith baseados nas vantagens absolutas, naturais ou adquiridas. Conforme se salientou, de acordo com este autor, a base do comércio internacional deveria ser a troca de mercadorias cujos preços (determinados pela quantidade de trabalho incorporado) fossem menores do que o praticado no mercado interno. Assim, dever-se-ia adquirir no exterior tudo o que fosse mais barato comprar do que produzir internamente. Exportavam-se manufaturas, cuja vantagem inglesa era superior, e importavam-se cereais da Polônia, cujas terras férteis e mais baratas permitiam uma maior produção a um menor custo que na Inglaterra.

Para Ricardo, entretanto, o comércio exterior deveria ser estimulado, mesmo se um país pudesse auferir maior vantagem do que outro, simultaneamente, tanto na produção agrícola como na industrial. Mas, como justificar isto? Tome-se o exemplo do próprio autor, que estrutura um modelo em que se relacionam duas mercadorias, tecido e vinho, comparando seus custos de produção entre dois países, no caso Portugal e Inglaterra ${ }^{16}$. Como forma de obter um denominador comum para comparar custos, utiliza sua teoria do valor-trabalho, definindo os custos em horas de trabalho necessárias para a produção de uma unidade de cada mercadoria.

Na Inglaterra demanda-se, para a produção de uma unidade de tecido, 100 horas, enquanto que de vinho, 120 horas. Em Portugal, a produção de uma unidade de tecido demanda 90 horas e uma de vinho 80 horas. Valendo-se simplesmente da teoria das vantagens absolutas de Smith, o comércio entre Portugal e Inglaterra seria desaconselhável para os ingleses, uma vez que os portugueses apresentam vantagens na produção de ambas as mercadorias. Isto também poderia justificar uma série de medidas protecionista, visando a amparar a manufatura inglesa, livrando-a de um concorrente mais eficiente. $\mathrm{O}$ argumento de Ricardo, entretanto, não pára por aí.

Posteriormente, são definidas as razões entre os preços das duas mercadorias para cada país. Em Portugal, por exemplo, a razão entre o preço do vinho e o preço do tecido é da ordem de 0,88 (80/90) e, na Inglaterra, de 1,20 (120/100). Já a razão entre o preço do tecido em relação ao preço do vinho é de 1,12 (80/90) em Portugal, e 0,83 $(100 / 120)$ na Inglaterra.

Em Portugal, a produção de vinho precisa de $88 \%$ do trabalho exigido para a produção de tecido, logo, o preço do vinho equivale a apenas $88 \%$ do preço do tecido. Já, na Inglaterra, o preço do vinho equivale a $120 \%$ do preço do tecido. Isto quer dizer que, em termos relativos, Portugal usa menos trabalho na produção de vinho, e o preço é relativamente mais baixo. Por outro lado, Portugal usa $112 \%$ do trabalho incorporado à produção de vinho para produzir tecido, enquanto que, na Inglaterra, o preço do tecido equivale a apenas $83 \%$ do trabalho necessário à produção de vinho. Logo, o preço do tecido na Inglaterra é relativamente mais baixo que o de Portugal.

Para Ricardo, o livre-comércio sempre seria preferível, se cada país pudesse se especializar na produção da mercadoria em que possuísse uma maior vantagem comparativa. A Portugal seria in-

\footnotetext{
${ }^{15}$ RICARDO, David. Princípios de economia política e da tributação. São Paulo: Abril Cultural, 1982. p. 44. (Coleção Os Economistas)

${ }^{16} \mathrm{O}$ exemplo de Ricardo não deixa de causar impressão para um pesquisador brasileiro. $\mathrm{O}$ autor toma como exemplo justamente os produtos objetos de um acordo comercial entre Inglaterra e Portugal, assinado em 1703: o Tratado de Methuen. Naquele acordo, definia-se que o vinho português tinha preferência de acesso ao mercado inglês, enquanto que os tecidos ingleses teriam preferência de acesso ao mercado português. Ocorre que, durante a vigência do acordo (a maior parte do século XVIII), a balança comercial portuguesa apresentou enormes déficits comerciais cobertos pela produção brasileira de ouro. A respeito do papel da mineração brasileira na acumulação industrial inglesa, ver: SIMONSEN, Roberto C . História econômica do Brasil: 1500-1810. São Paulo: Cia. Editora Nacional, 1976.
} 
teressante produzir vinho para comprar tecido inglês, enquanto que, para a Inglaterra, seria mais proveitoso produzir tecido e comprar vinho português. Mas como isso seria possível?

Suponha-se que os portugueses só estivessem produzindo vinho (a mercadoria em que têm maior vantagem comparativa) e resolvessem comprar tecido. Haveria duas maneiras de conseguir tecido: a) desviando algum trabalho da produção de vinho para a produção de tecido; b) trocando vinho por tecido com a Inglaterra. Agora, suponha-se que, em havendo comércio, ele fosse feito na razão de preços da Inglaterra. Como se viu, para os portugueses produzirem uma unidade de tecido, são necessárias 90 horas de trabalho. Isto quer dizer que estes teriam que interromper a produção de 1,12 unidades de vinho, para cada unidade de tecido que produzissem, mas se trocassem com a Inglaterra, só precisariam abrir mão de 0,83 unidade de vinho para cada de tecido. Por tal exemplo, o comércio com a Inglaterra deixaria os portugueses com uma maior quantidade de vinho e tecido.

Da mesma forma, se a Inglaterra somente produzisse tecido, mas pudesse trocá-los à razão dos preços de Portugal, não deveria produzir vinho. Se o produzisse, teria de abrir mão de 1,2 unidades de tecido para cada unidade de vinho, ao passo que, comerciando com os portugueses, somente abriria mão de 0,88 unidade de tecido para cada unidade de vinho. Por tal modelo, portanto, o comércio internacional e a especialização no produto com maior vantagem comparativa seria plenamente justificável, uma vez que tanto Portugal como Inglaterra poderiam adquirir uma maior quantidade de produtos utilizando de forma mais racional o trabalho em cada país. A defesa do livre-comércio, finalmente, seria justificada como uma forma de harmonizar as nações e difundir entre todas os benefícios alcançados pela especialização. Veja-se como Ricardo trata desta questão:
"Num sistema comercial perfeitamente livre, cada país naturalmente dedica seu capital e seu trabalho à atividade que the seja mais benéfica. Essa busca de vantagem individual está admiravelmente associada ao bem universal do conjunto dos países. Estimulando a dedicação ao trabalho, recompensando a engenhosidade e propiciando o uso mais eficaz das potencialidades proporcionadas pela natureza, distribui-se o trabalho de modo mais eficiente e mais econômico, enquanto, pelo aumento geral do volume de produtos, difunde-se o benefício de modo geral e une-se a sociedade universal de todas as nações do mundo civilizado por laços comuns de interesse e de intercâmbio". ${ }^{17}$

A teoria das vantagens comparativas de David Ricardo ainda é a base para o discurso liberal de livre-comércio e especialização, em que pese estar fundamentada na teoria do valor-trabalho. Por conta do uso que Marx fez deste conceito, chegando a conclusões como a teoria da maisvalia, a interpretação do mecanismo de formação de preços baseado no valor-trabalho foi abandonada pelos economistas neoclássicos. Veja-se como o professor Ellsworth apresenta as supostas limitações da teoria de Ricardo:

"O princípio dos custos comparativos há mais de um século tem sido muito útil como instrumento de análise, e com as necessárias restrições pode ser aplicado a um grande número de problemas. Sofre, entretanto, do sério defeito de basear-se na teoria do valortrabalho e, assim, de ser expresso em termos de um único fator - o trabalho. (...) É um erro limitar os insumos apenas ao trabalho, uma vez que, como se sabe muito bem, há muitos fatores de produção e mesmo o trabalho não é um fator único e homogêneo". ${ }^{18}$

Autores neoclássicos, como Léon Walras, William Stanley Jevons e Carl Menger, no começo da década de 1870 , publicaram estudos em que, na visão destes, suplantavam a teoria do

\footnotetext{
${ }^{17}$ RICARDO, op. cit., p. 104.

${ }^{18}$ ELLSWORTH, P. T. Economia internacional: teoria e prática, desde o mercantilismo até a formação do Mercado Comum Europeu. São Paulo: Atlas, 1971. p. 78
} 
valor-trabalho, ao adotar a teoria utilitarista ${ }^{19}$ para a formação dos preços no mercado: a utilidade marginal. Segundo um historiador do pensamento econômico:

"A noção de utilidade marginal decrescente (...) permitiu que Jevons, Menger e Walras e seus sucessores mostrassem, concreta e explicitamente, como a utilidade determinava os valores(...). O marginalismo permitiu que a visão utilitarista da natureza humana, que era considerada somente uma maximização racional e calculista da utilidade, fosse formulada em termos de cálculo diferencial". ${ }^{20}$

$\mathrm{Na}$ verdade, o raciocínio acima citado é incompleto, porque o fenômeno é inverso: a teoria utilitarista é um artifício de raciocínio para permitir incorporar as vantagens do cálculo diferencial à economia burguesa. Contudo, os procedimentos do cálculo diferencial nada têm a estabelecer com as premissas do utilitarismo que são, evidentemente, metafísicas, eternas, a-históricas e apologéticas ao sistema vigente.

Baseados nos postulados neoclássicos, economistas como Eli Pilip Heckscher, Bertil G. Ohlin e Gottfried Haberler buscaram repensar a teoria das vantagens comparativas. Por esses postulados, o preço de uma mercadoria é determinado pela soma de todos os fatores que entram na sua produção. Heckscher e Ohlin concluíram que os preços relativos destes fatores determinam as exportações ou importações dos países e também que estes preços são determinados pela maior ou menor abundância em um dado país. Tais fatores poderiam ser a terra, os minérios, o capital ou o trabalho. O comércio internacional seria, desta forma, apenas a troca de fatores abundantes por fatores raros. Relacionando esta definição à teoria das vantagens comparativas, por meio do "Teorema Heckscher-Ohlin", os autores concluíram que um determinado país deveria especializar-se na produção de mercadorias em que obtivesse uma vantagem comparativa no fator mais abundante ${ }^{21}$.

Já Gottfried Haberler, valendo-se principalmente da teoria do equilíbrio geral, reformulou a teoria das vantagens comparativas no comércio, substituindo a análise baseada no valor-trabalho pelas combinações possíveis de quantidades de bens que podem ser produzidos com quantidades específicas de fatores de produção, em um país determinado. Valendo-se de instrumental matemático, formulou, assim, uma Curva de Substituição dos dois produtos, também chamada "curva de limite de produção possível", que descarta toda a referência à teoria do valor-trabalho, considerando simultaneamente vários fatores de produção e permitindo identificar quais os ganhos e as desvantagens do comércio internacional. Com a palavra Haberler:

"Uma das principais objeções sempre feitas à teoria clássica é que esta supõe o trabalho como o único e universal fator de produção e que este é dotado de completa mobilidade. Este é um defeito grave, porque, afinal, parece perfeitamente claro que há não um, mas diversos fatores de produção e que alguns são verdadeiramente imóveis no espaço ou utilizáveis unicamente para fins específicos, o que vale dizer, somente podem ser empregados em um número limitado de formas. O próprio fator 'trabalho' não é móvel nem homogêneo entre ocupações ou localidades, especialmente em curto prazo". ${ }^{22}$

\footnotetext{
${ }^{19}$ Do ponto de vista filosófico, o utilitarismo propõe que o bem está identificado com o útil. Um dos defensores de tal princípio, Jeremy Bentham, postula que o objetivo de todas as ações humanas é evitar a dor e proporcionar prazer. Tal ponto de vista aplicado à economia implicaria que o que determina o preço de uma mercadoria é o nível de utilidade que o consumidor lhe confere. Quanto maior a utilidade ou a satisfação proporcionadas por um bem, maior o preço a ele atribuível.

${ }^{20}$ E.K. HUNT, op. cit., p. 279.

${ }^{21}$ A universalidade dos postulados do "Teorema Heckscher-Ohlin" foi contestada por R.W. Jones, após este analisar a matriz "imput-output" de Leontief, em que este mostrava que as exportações dos Estados Unidos eram mais trabalho-intensivas do que capital-intensivas, o que aparentemente seria uma incongruência. Ver: JONES, R.W. Proporções de fatores e o Teorema Heckscher-Ohlin. In: SAVASINI, José Augusto A. et al. Economia Internacional. São Paulo: Saraiva-ANPEC, 1979. p. $33-63$.

${ }^{22}$ HABERLER, Gottfried. A teoria clássica dos custos comparativos e dos valores internacionais de Hume e Marshall. In: SAVASINI, José Augusto A. et al. Economia Internacional. São Paulo: Saraiva; ANPEC, 1979. p. 9.
} 
As supostas debilidades da teoria das vantagens comparativas apresentadas pelos autores neoclássicos suscitam problemas de duas ordens: (a) em que medida ainda é válida a teoria do valor-trabalho, e quais suas implicações sobre o comércio internacional?; (b) quais as reais insuficiências da teoria das vantagens comparativas? Procurar-seá discutir tais problema a seguir.

\subsection{Considerações sobre a validade da teoria do valor-trabalho}

As teorias que definem o valor de troca de uma mercadoria, desde Adam Smith, dividem-se naquelas que privilegiam o trabalho humano como componente único para a determinação do valor "natural" de uma mercadoria (neste campo desfilam Smith, Ricardo, Malthus e Marx). Por outro lado, aquelas que determinam o valor de troca a partir da utilidade (ou satisfação) proporcionada ao consumidor (tal como a definem Say, Mill e os autores neoclássicos). A primeira procura dar uma explicação científica ao fenômeno, a segunda, uma explicação "psicológica".

Partindo da premissa da utilidade, JeanBaptiste Say formulou a tese de que para a produção de uma mercadoria seriam necessários o concurso de três fatores, quais sejam: o capital, o trabalho e os agentes naturais (terra, minas, florestas). A estes três fatores de produção, economistas posteriores adicionaram a organização empresarial e a ciência/tecnologia. Ora, se analisarmos a fundo cada um dos fatores acima citados, qual deles, em sua essência, não decorre do trabalho humano?

Por mais simplista que possa parecer aos autores neoclássicos, a teoria do valor-trabalho de Ricardo apresenta grande sofisticação ao considerar, no processo de formação do valor de troca das mercadorias, não somente o trabalho realizado diretamente pelo operário, ao qual denominou trabalho imediato, mas também o trabalho incorporado tanto nos equipamentos utilizados por este, como também aquele incorporado nas matérias-primas, o trabalho mediato. Veja-se como o autor justifica sua posição:

"Se considerarmos um estágio da sociedade no qual grandes progressos já foram realizados, e no qual florescem as artes e o comércio, observaremos que o valor das mercadorias também varia segundo este princípio: ao estimar o valor de troca das meias, por exemplo, descobriremos que o seu valor, comparado com o de outras coisas, depende da quantidade total de trabalho necessária para fabricá-las e lançá-las no mercado. Primeiro, há o trabalho necessário para cultivar a terra na qual cresce o algodão; segundo, o trabalho de levar o algodão ao lugar em que as meias são fabricadas - no que se inclui o trabalho de construção do barco no qual se fez o transporte e que é incluído no frete dos bens - ; terceiro, o trabalho do fiandeiro e do tecelão; quarto, uma parte do trabalho do engenheiro, do ferreiro e do carpinteiro que construíram os prédios e a maquinaria usados na produção; quinto, o trabatho do varejista e de muitos outros que não vem ao caso mencionar. A soma de todas essas várias espécies de trabalho determina a quantidade de outras coisas pelas quais as meias serão trocadas, enquanto a mesma consideração das várias quantidades de trabalho utilizado nesses outros bens determinará igualmente a porção deles que se dará em troca das meias". ${ }^{23}$

Tal definição, apresentada de forma clara, nos faz refletir sobre a origem de todos aqueles fatores, mesmo naqueles em que aparentemente não existe, há o trabalho humano incorporado, como nas florestas, minas ou solos aráveis. Sem o objetivo de transformar a Natureza no sentido de dela extrair alimentos e matérias-primas para serem utilizadas no processo de produção e reprodução social, não faz sentido a sua preexistência, do ponto de vista estritamente econômico. $\bigcirc$ que lhe confere importância, é o trabalho humano que com ela se interage. De acordo com Marx:

"Antes de tudo, o trabalho é um processo entre o homem e a Natureza, um processo em que o homem, por sua própria ação, media, regula e controla seu

\footnotetext{
${ }^{23}$ RICARDO, op. cit., p. 50.
} 
metabolismo com a Natureza. Ele mesmo se defronta com a matéria natural como uma força natural. Ele põe em movimento as forças naturais pertencentes à sua corporalidade, braços e pernas, cabeça e mão, a fim de apropriar-se da matéria natural numa forma útil para sua própria vida". ${ }^{24}$

Outro fator considerado pelos utilitaristas, o capital, observado também em sua essência, não passa senão de trabalho acumulado, principalmente por intermédio da expropriação de parte do trabalho do operário. De acordo com Marx, a jornada de trabalho do operário se divide em dois períodos. No primeiro, ele cria o valor necessário para garantir os meios de sua subsistência. Já no segundo período do processo de trabalho, cria um valor que não lhe é pago, em que pese que isto lhe custe o seu esforço. Conforme o autor, este segundo período...

"... gera a mais-valia, que sorri ao capitalista com todo o encanto de uma criação do nada. Essa parte da jornada chamo de tempo de trabalho excedente, e o trabalho despendido nela: mais-trabalho (surplus labour). (...) Apenas a forma pela qual esse mais-trabalho é extorquido do produtor direto, do trabalhador, diferencia as formações sócio-econômicas, por exemplo a sociedade da escravidão da do trabalho assalariado". 25

O processo de formação do capital, ao longo do tempo, sempre pressupôs a apropriação de parte do excedente produzido pelo trabalhador direto, fosse na Roma antiga, num feudo na Renânia ou numa plantação de cana-de-açúcar no Brasil colonial.

Os demais fatores, a estrutura organizacional e a tecnologia não passam também de trabalho humano, neste caso, de ordem intelectual. Cabe ressaltar que estes.fatores somente encontram sua razão de ser, quando empregados no processo produtivo, mas sempre com repercussões sobre a quantidade de trabalho necessária à produção de mercadorias. Sem a crescente necessidade de inovação que exige a concorrência oligopolística dos dias atuais, o ritmo das transformações oriundas desses fatores seria significativamente menor.

Diante do exposto, por mais que se possa produzir um discurso (e toda uma metodologia) que vise a atacar a teoria do valor-trabalho, esta ainda continua sendo útil como definição científica para a explicação da formação do valor de troca das mercadorias. Concluindo, a crítica à teoria das vantagens comparativas não deveria ser feita abandonando-se um princípio considerado adequado. Acredita-se que a crítica às formulações de Ricardo deve considerar outras questões, tais como a sua a-historicidade, a forma como são difundidos os padrões de consumo ocidentais e, por fim, o problema da troca desigual.

\section{As limitações da teoria das vantagens comparativas}

Os críticos de um modelo teórico qualquer sempre insistem que a realidade é muito mais complexa do que aquilo que se procura explicar por seu intermédio. Isto é evidente e acredita-se que nenhum pesquisador sério pense diferente disto. Ocorre que, diante da realidade, que insiste em apresentar-se tão caótica e ininteligível, a criação de modelos explicativos ajuda-nos a compreendê-la dentro de alguma ordem racional. Isto, em si, é uma grande contribuição para a ciência. Os modelos em ciências sociais, entretanto, carecem de abrangência, uma vez que explicam um dado momento, desde que as demais variáveis não mudem, a tal condição caeteris paribus. $\bigcirc$ que pode explicar uma situação num determinado contexto histórico pode não explicá-la em outro. Mas esta advertência não deve ser feita a quem pensou sobre a realidade num dado momento, mas sim a quem insiste em conferir a isto um caráter universal e a-temporal. É este o principal problema do modelo de David Ricardo acerca das vantagens comparativas.

Deve-se considerar que o modelo de Ricardo visa a retratar um momento específico na relação

\footnotetext{
${ }^{24}$ MARX, Karl. O capital: crítica da economia política. São Paulo: Nova Cultural, 1985. v. 1, t. 1, p. 149. (Coleção Os Economistas)

${ }^{25}$ Idem, p. 176-177. (grifo do autor)
} 
comercial de dois países. Desta forma, abandona a possibilidade de o país mais pobre almejar o progresso tanto de sua produção agrícola quanto industrial. Por "progresso", neste caso específico, considera-se a elevação da produtividade do trabalho, o que, em teoria, seria o objetivo de todas as economias capitalistas. Historicamente, tem-se verificado nos dois últimos séculos uma elevação acentuada na produtividade industrial, e, a partir desta, uma série de inovações que permitiram também o aumento da produtividade agrícola. A superioridade de uma economia industrial sobre uma agrícola vem sendo ressaltada desde os tempos de Adam Smith, conforme segue:

"As nações mais opulentas geralmente superam todos os seus vizinhos tanto na agricultura como nas manufaturas; geralmente, porém, distinguem-se mais pela superioridade na manufatura do que pela superioridade na agricultura. Suas terras são mais bem cultivadas, e, pelo fato de investirem mais trabalho e mais dinheiro nelas, produzem mais em proporção à extensão e à fertilidade natural do solo.(...) Na agricultura, o trabalho do país rico nem sempre é muito mais produtivo do que o dos países pobres, ou, pelo menos, nunca é mais produtivo na mesma proporção em que o é, geralmente, nas manufaturas.(...) Todavia, embora um país pobre, não obstante a inferioridade no cultivo das terras, possa, até certo ponto, rivalizar com os países ricos quanto aos baixos preços e à qualidade do trigo, jamais poderá enfrentar a competição no tocante às suas manufaturas; ao menos se essas indústrias atenderem às características do solo, do clima e da situação do país rico" ${ }^{26}$

Além desta questão, pode-se colocar um problema de outra ordem, relacionado à falta de perspectiva histórica: trata-se da deterioração dos termos de troca. Este fenômeno foi analisado por Raul Prebisch, ao comparar o preço de exportação dos bens primários (produzidos por economias periféricas) com os preços dos bens industrializados (produzidos nos países centrais). Pre- bisch constatou que, a longo prazo, os preços dos primeiros tendem a reduzir-se com maior velocidade que os dos segundos. Uma das causas levantadas pela CEPAL para explicar esta tendência é a diferença da produtividade da mão-de-obra entre os setores primário e secundário. Esta tendência à deterioração se manifesta através das flutuações cíclicas da economia mundial, características do capitalismo, prejudicando o desenvolvimento das economias especializadas na produção de bens primários. Segundo Rodriguez:

"Durante as fases de auge, os preços primários aumentam mais de que os preços industriais, porém baixam mais nas fases de declínio. Esta baixa é tão maior que os preços dos produtos de exportação da periferia perdem, durante as fases de contração, mais do que haviam ganho (sic) nas fases de auge. Dessas variações conjunturais resulta a tendência à deterioração a longo prazo dos termos de intercâmbio". ${ }^{27}$

Outro raciocínio que reforça esta tendência para a deterioração dos termos de troca dos países especializados na produção de bens primários está no fato de as nações industrializadas ditarem o padrão de consumo para as sociedades periféricas. Por conta de diversos mecanismos de comunicação de massa, os padrões de consumo dos países ricos são difundidos na periferia, atingindo em cheio o "desejo" de consumo das elites destes países. A variedade de bens que foram introduzidos nos últimos cinqüenta anos oferece uma leve idéia do poder sedutor do padrão de consumo "ocidental" ou, se preferirem, do american way of life: automóveis, televisores, gravadores, aparelhos de som, walkmans, computadores pessoais, telefones móveis, calçados esportivos etc..

A estratégia de mercado adotada pelas grandes empresas multinacionais, as principais responsáveis por essa "universalização" do padrão de consumo ocidental, é direcionada para a obtenção do maior lucro possível, através da continuada introdução de novos produtos. Para

\footnotetext{
${ }^{26}$ SMITH, op. cit., p. 67.

${ }^{27}$ RODRIGUEZ, Octávio. Teoria do subdesenvolvimento da CEPAL. Rio de Janeiro: Forense-Universitária, 1981. p. 41.
} 
tanto, fazem uma análise detalhada do "ciclo de vida" de cada um, de forma a identificar o momento em que o mercado de determinado bem entra em saturação, para que novos produtos sejam lançados em seu lugar, impedindo, assim, a perda de lucratividade da empresa ${ }^{28}$.

Pode ser citado como exemplo, de certa forma hipotético, o ciclo de vida de um aparelho de vídeo-cassete. Quando de seu lançamento no mercado, o preço do aparelho deveria ser o mais alto possível, visando ao rápido abatimento dos investimentos em pesquisa e produção. Como se tratava de uma inovação, seu preço estava adequado ao padrão de consumo das famílias de alto rendimento (renda $\mathrm{A}$ ), as primeiras a adquirir a "novidade". Quando este segmento já estava saturado, foi inventado o aparelho de duas cabeças, destinado a este mesmo segmento, mantendo-se o preço do produto. Entretanto, o aparelho de uma cabeça teve seu preço reduzido, visando a atingir famílias de renda média (renda B), de forma a alargar o mercado consumidor e manter a lucratividade. Note-se que, quando se atingiu tal situação, a fábrica de vídeo já pôde compensar seus custos de desenvolvimento de produto, colocando o bem a um menor preço mas com grande margem de lucro. Num terceiro momento, quando os mercados "A" e "B" já se encontravam saturados, foi inventado o aparelho de quatro cabeças, novamente destinado às famílias de renda (A). O aparelho de duas cabeças teve seu preço adequado ao orçamento das famílias de renda (B), e o aparelho de uma cabeça teve seu preço novamente reduzido, visando ao mercado das famílias de menor rendimento (C). Num quarto momento, quando o aparelho não comportava mais nenhuma inovação significativa, a indústria de eletrônicos mudou o paradigma tecnológico e inventou o DVD Player, aparelho para a leitura de discos digitais de alta densidade, o sucedâneo do vídeo-cassete. Feito isso, reinicia-se o ciclo do produto, começando a oferecer a novidade às famílias de alta renda (A).

A introdução de novos produtos industriais contrasta com a suposta rigidez da pauta dos chamados bens primários. Café, açúcar, trigo, soja, frutas, lã, algodão, minerais, petróleo etc., já constavam da pauta do comércio internacional no final do século XIX. Isto fez (e faz) com que os países especializados na produção de bens primários apresentassem grande dificuldade para a manutenção ou melhoria dos padrões de consumo de suas populações ${ }^{29}$. Mas este não é o único problema advindo da especialização ricardiana.

A especialização no comércio internacional, baseada na produção de alimentos e matériasprimas, também apresenta inconvenientes, como a inelasticidade-renda do consumo de alimentos, verificada nos países de alta-renda, e a crescente diminuição da importância das matérias-primas naturais diante da grande produção de materiais sintéticos, assim como da introdução de nanotecnologias.

Em relação ao primeiro problema, tomam-se emprestadas as conclusões do economista alemão Ernest Engel, depois de analisar a composição do consumo familiar. Naquele estudo, verificou a existência de uma relação direta entre a renda familiar e os gastos com alimentação. Engel constatou que nas famílias com rendimentos mais elevados o montante gasto com alimentação, a partir de certo patamar, não aumenta na mesma proporção que um dado aumento de renda. A representação gráfica desta tendência ficou conhecida como "Curva de Engel”. Tal definição é importante para repensar o problema da especialização, uma vez que o expressivo aumento da renda pessoal nos países industrializados, a partir do final do século XIX, não foi acompanhada pelo aumento do consumo de alimentos produzidos pelos países agrícolas.

\footnotetext{
${ }^{28} \mathrm{O}$ conceito de "ciclo de vida" de um produto foi desenvolvido pela administração de marketing para a definição de estratégias mercadológicas. O ciclo de um produto é caracterizado por cinco etapas: introdução, crescimento, maturação, saturação e declínio. A este respeito, consultar: KOTLER, Philip. Administração de Marketing. São Paulo: Atlas, 1990.

${ }^{29}$ Um saco de café de 1870 não é senão na aparência similar a outro de 1970. Isto parece óbvio, mas talvez haja mais tecnologia nova embutida num produto aparentemente "primário", como a laranja, do que num queijo como o "brie".
} 
Por outro lado, o gasto com artigos industrializados e serviços apresentou uma variação positiva em relação ao aumento da renda, fato comprovado pela grande inovação tecnológica verificada no mesmo período, pela diminuição gradativa da jornada de trabalho (liberando maior tempo para o lazer), do incremento do ingresso de mulheres no mercado de trabalho e pela "mercantilização" de uma série de tarefas que anteriormente eram realizadas no âmbito do domicílio. Lavanderias, restaurantes, comidas congeladas, turismo, parques de diversão etc., são exemplos de como o consumo familiar se deslocou ao longo deste último século.

A especialização baseada na produção de matérias-primas também vem sendo negativamente prejudicada pelas grandes transformações verificadas na economia capitalista ao longo do último século. $\mathrm{O}$ consumo industrial de ferro, alumínio, cobre, carvão, petróleo, madeira etc. vem sendo influenciado por pressões para a redução de custos e preservação ambiental, além da crescente inovação tecnológica. Materiais sintéticos, como plásticos e fibras, têm substituído com grande economia metais, madeiras e vidros. As nanotecnologias, desenvolvidas em grande escala a partir da crise econômica dos anos 70, também são responsáveis pela diminuição da demanda por matérias-primas. A este respeito, valemo-nos da opinião de Coates:

"As forças sociais vêm actuando no sentido de pressionar um bom número de criações humanas para uma resistência acrescida e uma duração de vida mais longa, apelando a um maior recurso à reciclagem, à recuperação e ao recondicionamento. As pressões ecológicas, a falta de recursos e os meios técnicos contribuíram para impor sistematicamente a resistência e os outros três critérios evocados no mundo inteiro.

Os materiais evoluem, para a miniaturização $e$ para as estruturas modulares. Os pequenos módulos utilizam menos materiais e menos energia e são fáceis de substituir, podendo, por outro lado, a reparação e a recuperação serem centralizadas. Quanto à miniaturização, esta vai para além da concepção de aparelhos que cabem numa mão ou na ponta de um dedo. São já comercializados dispositivos microscópicos, mais pequenos que o diâmetro de um cabelo.(...) As micromáquinas abrem uma via a um mundo hipotético, mil vezes mais pequeno do que o domínio microscópico(...) O objetivo das nanotecnologias, levadas ao extremo, é de proceder por analogia com a natureza.(...) A fabricação de materiais biomiméticos, imitando produtos naturais ou análogos a estes, oferece uma outra pista para a revolução dos materiais". 30

A evolução tecnológica, verificada no desenvolvimento de novos materiais ou de novas fontes de energia, leva, necessariamente, à diminuição da demanda mundial de matérias-primas, constituindo um grande problema potencial para os países que se especializaram na produção de tais artigos. Tendencialmente, para estas nações, depender da exportação de bens primários significa diminuir a renda interna e o poder de compra no exterior. Apesar de tudo isto, os problemas decorrentes da especialização são ainda de maior envergadura.

O comércio internacional, baseado na especialização, tende a aumentar a diferença de rendimentos entre os países primário-exportadores e os industrializados. Uma explicação adicional estaria no conceito desenvolvido por Arghiri Emmanuel de troca desigual. Segundo esta definição, as relações comerciais entre os países do centro e da periferia seriam desiguais, porque o preço das mercadorias produzidas nos países periféricos seriam artificialmente formados a partir de baixos salários, comparativamente aos bens dos países centrais. ${ }^{31}$ De acordo com Emmanuel:

"Os salários diferenciam-se por zonas geográficas e independentemente das flutuações das bolsas de mer-

\footnotetext{
${ }^{30}$ COATES, Joseph. A tecnologia dos próximos 25 anos: perspectivas e factores de risco. In: OCDE. As tecnologias do século XXI: ameaças e desafios de um mundo dinâmico. Lisboa: GEPE; Ministério da Economia, 2000. p. 66-67.

${ }^{31}$ É evidente que, quando os neoclássicos abandonam a teoria do valor-trabalho, adotando a concepção dos "fatores de produção", deliberadamente procuram escamotear os problemas da troca desigual baseada em salários artificialmente baixos praticados nos países periféricos.
} 
cadorias. São rígidos e notavelmente estáveis no tempo. Durante os últimos vinte anos, as cotações do café, do cobre e do açúcar, têm triplicado e, às vezes, muito mais. A isto não há correspondido nenhuma variação dos salários, nem próxima nem distante, que haja sido registrada nos países produtores. Através de todas essas evoluções ou revoluções dos preços, o trabalhador da Guiné, de Uganda, do Brasil ou Katanga, não deixa de obter o salário de subsistência, que se pode estimar, sem grande margem de erro, em 5 centavos de dólar norte-americano por hora, ainda que o de seu homólogo norte-americano ou europeu se aproximava, durante esse mesmo tempo, a uma quantidade 20, 30 ou 40 vezes maior, uma vez mais segundo o país e em nenhuma forma segundo as flutuações dos preços. Durante esse mesmo período, o capitalista da Guiné, de Uganda, do Brasil ou Katanga teria, evidentemente, altas e baixas, porém um ano por outro, ao fim de um periodo tem auferido lucros que não estão distantes da taxa média internacional". ${ }^{32}$

A troca desigual é estabelecida ao considerar que somente a remuneração de um único "fator" (tomando emprestado a definição neoclássica), o trabalho, está sujeito às especificidades nacionais, enquanto que o capital é remunerado a uma taxa de média de lucro internacional. Tais "especificidades nacionais" dos países do chamado Terceiro Mundo, como a História ensina, foi criado por rastros de destruição, pilhagem e escravidão deixados pelos colonialistas europeus. Por que remunerar bem as gentes de cor da América Latina, Ásia e África? Elas já não se acostumaram a viver próximas da subsistência?

Utilizando o conceito da troca desigual, Samir Amin analisa a teoria das vantagens comparativas de Ricardo, indicando que ela inconscientemente leva à troca desigual. Amin vale-se do mesmo modelo de Ricardo, a produção de pano e vinho em dois países distintos, Portugal e Inglaterra. Entre- tanto, o autor inverte os termos da relação, de forma a aproximá-los da realidade (maior produtividade inglesa). Desta forma, uma unidade de pano na Inglaterra demandaria 80 horas e uma unidade de vinho 90 horas, ao passo que, em Portugal, uma unidade de pano demandaria 120 horas e uma unidade de vinho 100 . Veja-se suas conclusões:

"Suponhamos que Portugal aceite especializar-se em vinhos e a Inglaterra lhe imponha seus panos. Se em Portugal a força de trabalho total disponivel for de 1.000 horas e o consumo de vinho for rígido (5 unidades), Portugal consagrará 500 horas de trabatho na produção de vinho para seu consumo. Disporá de 500 horas que poderá utilizar, seja em produzir seu próprio pano (500: $120=4,2$ unidades), seja em produzir mais 5 unidades de vinho, com as quais obterá 5 unidades de pano: ganhou 0,8 unidades de pano na troca. Contudo, embora tenha ganho em valores de uso, terá empregado 500 horas para obter 5 unidades de pano que a Inglaterra produziu em 400 horas. Sua hora se intercambiará com 0,8 hora inglesa: a troca é desigual. A desigualdade da tro$c a-$ em valor de troca - expressa a menor produtividade do trabalho em Portugal". ${ }^{33}$

Considerando, segundo Amin, que as diferenças de produtividade entre os países deve-se a um problema de ordem histórica, quando o "país atrasado" progride, tais diferenças tendem a diminuir. Se Portugal, por exemplo, optasse por modernizar-se, de tal forma a alcançar a produtividade da Inglaterra, as trocas entre os dois países deixariam de ser vantajosas. Isto porque poderia produzir 5 unidades de vinho com apenas 450 horas $(90 \times 5=450)$, restando-lhe 550 horas com as quais poderia produzir 6,9 unidades de pano (550: $80=6,9)$. Isto representaria um ganho de 1,9 unidades de pano em comparação com a estratégia de especialização na produção de vinhos. Tal resultado não seria alcançado, mesmo

${ }^{32}$ EMMANUEL, Arghiri. El intercambio desigual: ensayo sobre los antagonismos en las relaciones económicas internacionales. México (DF): Siglo Veintiuno Editores, 1972. p. 107. (tradução minha)

${ }^{33}$ AMIN, Samir. O comércio internacional e os fluxos internacionais de capital. In: EMMANUEL, A. et al. Imperialismo e comércio internacional: a troca desigual. São Paulo: Global, 1981. p. 99. (grifo nosso) 
se Portugal tentasse alcançar a produtividade da Inglaterra apenas na produção de vinhos, já que seriam necessárias 450 horas para o seu autoconsumo, restando 550 horas para a produção adicional de 6,1 unidades de vinho (550:90), possibilitando a aquisição de apenas 6,1 unidades de pano. Desta forma, propõe Samir Amin:

“... o interesse superior [de um país] baseia-se em desenvolver os ramos de produção nos quais o progresso possivel for maior e em submeter as opções em matéria de comércio exterior a exigências prioritárias desse desenvolvimento. Trata-se, certamente, de uma concepção agressiva das relações internacionais, mas corresponde, como veremos, à história e à situação atual". ${ }^{34}$

Concluindo este artigo, é importante frisar que as políticas que preconizam as vantagens da especialização no comércio internacional estão enviesadas pelos interesses das nações industrializadas e os teóricos do "livre-comércio" nada mais fazem do que retórica para conferir um caráter científico a problemas de ordem políticoeconômicos. Faz-se necessário frisar que, apesar de oferecer uma explicação racional, tais teorias inscrevem-se dentro de uma cultura específica, o Ocidente europeu e suas ramificações, e serviram (e servem) para justificar uma situação em que o capitalismo ocidental pôde estabelecer-se como sistema internacional, submetendo, desde o seu florescimento no século XV, as demais formações econômicas existentes no mundo.

Quando se analisa a evolução do capitalismo europeu, verifica-se que a estruturação do comércio internacional serviu como instrumento de transferência de riquezas do mundo todo para a Europa. Verifica-se também que a base desta transferência estava na pilhagem, escravização e submissão dos povos da África, da Ásia, da América e da Oceania. A superioridade militar a serviço da acumulação particular foi e é o principal mecanismo de transferência de riquezas dos países periféricos para os países centrais.

\title{
REFERÊNCIAS BIBLIOGRÁFICAS
}

\begin{abstract}
AMIN, Samir. O comércio internacional e os fluxos internacionais de capital. In: A. EMMANUEL et al. Imperialismo e comércio internacional: a troca desigual. São Paulo: Global, 1981. p. 99.

COATES, Joseph. A tecnologia dos próximos 25 anos: perspectivas e factores de risco. In: OCDE. As tecnologias do século XXI: ameaças e desafios de um mundo dinâmico. Lisboa: GEPE- Ministério da Economia, 2000.

DENIS, Henri. História do pensamento econômico. Lisboa: Livros Horizonte, 1987.

DESCARTES, René. Meditações. São Paulo: Nova Cultural, 1991. (Coleção Os pensadores).

E.K. HUNT. História do pensamento econômico. Rio de Janeiro: Campus, 1981.

ELLSWORTH, P. T. Economia internacional: teoria e prática, desde o mercantilismo até a formação do Mercado Comum Europeu. São Paulo: Atlas, 1971.

EMMANUEL, Arghiri. El intercambio desigual: ensayo sobre los antagonismos en las relaciones económicas internacionales. México (DF): Siglo Veintiuno Editores, 1972.

GALBRAITH, John K. A era da incerteza. São Paulo: Pioneira, 1984.

HABERLER, Gottfried. A teoria clássica dos custos comparativos e dos valores internacionais de Hume e Marshall. In: SAVASINI, José Augusto A. et al. Economia Internacional. São Paulo: Saraiva; ANPEC, 1979.

HUBERMAN, Leo. História da riqueza do homem. Rio de Janeiro: Zahar, 1971.

JONES, R. W. Proporções de fatores e o Teorema Heckscher-Ohlin. In: SAVASINI, José Augusto A. et al. Economia Internacional. São Paulo: Saraiva; ANPEC, 1979.

KOTLER, Philip. Administração de marketing. São Paulo: Atlas, 1990.

MARX, Karl. O capital: crítica da economia política. São Paulo: Nova Cultural, 1985.

RICARDO, David. Princípios de economia política e da tributação. São Paulo: Abril Cultural, 1982. (Coleção Os Economistas). RODRIGUEZ, Octávio. Teoria do subdesenvolvimento da CEPAL. Rio de Janeiro: Forense-Universitária, 1981.

SIMONSEN, Roberto C. História econômica do Brasil: 1500-1810. São Paulo: Cia. Editora Nacional, 1976.

SMITH, Adam. A riqueza das nações. Tradução Luiz J. Baraúna. São Paulo: Nova Cultural, v. 1. 1996. (Coleção Os Economistas).
\end{abstract}

${ }^{34}$ AMIM, op. cit., p. 100. 